Original scientific paper

\title{
SIMULATION-BASED MOULD DESIGN, LIFE PREDICTION AND RELIABILITY ASSESSMENT OF A VALVE BODY
}

\author{
Khan, M. A. A. ${ }^{*} \&$ Sheikh, A. K.** \\ * Mechanical Engineering Department, Prince Mohammad bin Fahd University, Khobar, Saudi Arabia \\ ** Mechanical Engineering Department, King Fahd University of Petroleum and Minerals, Dhahran, \\ Saudi Arabia \\ E-Mail: mkhan6@pmu.edu.sa, anwarks@kfupm.edu.sa
}

\begin{abstract}
Shrinkage porosities are one of the major casting defects which affects the quality and structural integrity of cast products. Consequently, the service life and reliability of the components are questioned and need to be determined prior to put these parts in service. This study presents a simulation based methodology for mould design, life prediction, and reliability assessment of castings using simulation tools. The methodology is developed and validated for standard test specimens followed by its application on a valve body. The mould design is optimized for porosities using MAGMASoft. Integration of predicted minimum porosity to valve body is done using MAGMAlink. The stress fields with porosity are obtained using ABAQUS which are then used to predict life and estimate reliability. Infinite life i.e. more than $10^{6}$ cycles is predicted with minimum porosity in valve body. The reliability results for valve under normal operating pressure i.e. $1 \mathrm{MPa}$ shows $\sim 100 \%$ reliability for infinite life, however, under the maximum loading conditions i.e. $2.5 \mathrm{MPa}$, the reliability is significantly compromised. A safe load-induced stress on valve is also determined based on the reliability results.

(Received in October 2020, accepted in March 2021. This paper was with the authors 3 months for 2 revisions.)
\end{abstract}

Key Words: Metal Casting, Mould Design, Simulation, Fatigue Life, Reliability, Optimization

\section{INTRODUCTION}

The use of ductile iron in sand casting is quite prevalent owing to its exceptional castability and excellent mechanical properties. Despite the fact that casting ductile iron is simple, if not properly designed, it may result in casting defects such as porosities which lead to compromised quality, service life and reliability of cast products. It is possible to control such defects through an optimized mould design, controlled chemical composition, and carefully selected process parameters. In present, such design features are analysed through software which can simulate the entire casting process and provides insights on multiple aspects such as filling, solidification, residual stresses, and defects etc. [1]. Once identified, the defects can be reduced or even eliminated in a virtual environment without going through physical casting process followed by traditional inspection methods. With the development of these computational tools over time, the processing time and cost of production are decreased together with improved quality and performance of the cast products.

The improvement in casting design using simulations is well reported in previously published literature [2-4]. Bhatt et al. optimized the manually designed feeding system to minimize shrinkage in a cast iron gear box. In total, ten trials were simulated by altering the diameter and height of the risers. The casting designs recommended were found to have minimum shrinkage together with improvement in yield i.e. $75 \%, 78 \%$, and $80 \%$ which was previously $\sim 72 \%$ in the existing method of casting. Sun et al. [3] presented the design optimization for a cast iron truck rear axle. Temperature and flow related defects were predicted using 3D FDM model and the Z-CAST software. Casting system was modified for the elements of gating system, simulated, and validated through experiments.

Mechanical characterization of ductile iron castings is also presented in various studies [5-8]. Mourad et al. [5] studied the microstructure and mechanical properties of ductile iron 
castings with heavy sections. The experimental work included casting of thick sections such as $100 \mathrm{~mm} \times 100 \mathrm{~mm}$ cross-section, microstructural examination, mechanical testing and fractography. It was inferred that matrix structure determines strength and impact properties along with mode of fracture during testing. Labrecque et al [8] determined the properties of thin-walled ductile iron castings including their fatigue characteristics. The strength values were found to be 448 and $440 \mathrm{MPa}$ for 4 and $6 \mathrm{~mm}$ respectively, with elongation values of 18 and $20 \%$. Also, the endurance limits measured for a $50 \%$ survival were found to be 453 and $430 \mathrm{MPa}$ for machined surfaces subjected to tensile stresses obtained from $4 \mathrm{~mm}$ and $6 \mathrm{~mm}$ castings respectively.

Hardin and Beckermann [9] developed a simulation based methodology to determine the fatigue life of castings containing shrinkage porosity. The porosity observed by X-ray tomography of specimens was reconstructed in the finite element simulations. It was reported that the fatigue lives of specimens vary by four orders of magnitude even with the same level of nominal stress and same average porosity. Hence, it was recommended to consider the amount as well as distribution pattern of porosity within the casting to simulate the actual mechanical performance. In another work by Hardin and Beckermann [10], casting simulation results were integrated to stress and mechanical performance simulations. Tensile and fatigue testing of specimens with porosity were simulated and compared with the experimental measurements performed on the specimens. A good agreement of simulation and experimental results led to a case study for design optimization of a real casting.

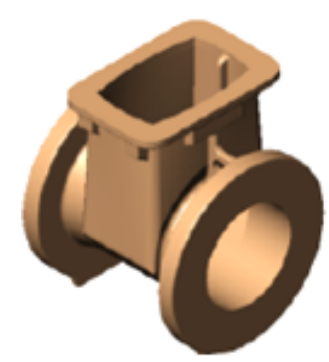

Figure 1: Ductile iron valve body.

The present study describes the development of a novel simulation-based methodology to determine the fatigue life and reliability of castings which are carefully produced with minimum defects using optimized mould design. It allows to perform cradle to grave analysis i.e. mould design to failure and even reliability analysis of castings in a completely virtual domain prior to any physical attempt of casting in a foundry and subsequent mechanical testing. For the purpose of this study, a ductile iron valve body is selected for which life and reliability needs to be estimated. The simulation-based methodology is developed and experimentally validated for standard tensile and fatigue specimens. Reliability of the specimens for already determined fatigue lives is computed and a window of safe load-induced stresses is developed. Next, this methodology is applied to the selected valve body as shown in Fig. 1, for which the mould design is optimized to minimize defects, fatigue life is predicted and reliability is calculated. Since, the methodology is already validated through experiments on the standard specimens, the valve is studied from mould design to failure and reliability using only simulations.

\section{MATERIALS AND METHODOLOGY}

The selected material for the valve body is a GGG-40 ductile iron which offers a good mix of mechanical and technological properties [11]. The composition and selected properties for this material are presented in Table I. The experimental setup to determine the structural integrity of an actual cast valve body is not only difficult to design but is also not economically feasible. Therefore, a simulation-based methodology is first developed and experimentally validated for 
standard tensile and fatigue specimens. This methodology is then applied to the valve body for performing a complete analysis from initial mould design to failure during service. Moreover, reliability of the valve body is also estimated for the loading conditions provided by the enduser. The steps followed in methodology development are shown in Fig. 2.

Table I: GGG-40 ductile iron material specification.

\begin{tabular}{|c|c|c|c|}
\hline \multicolumn{4}{|c|}{ Chemical Composition (Wt. \%) } \\
\hline $\mathrm{Fe}$ & $\mathrm{C}$ & $\mathrm{Si}$ & $\mathrm{Mn}$ \\
\hline 93.4 & 3.7 & 2.5 & 0.4 \\
\hline \multicolumn{3}{|c|}{ Mechanical Properties (at room temperature) } \\
\hline Yield Strength (MPa) & Tensile Strength (MPa) & Elongation (\%) \\
\hline 250 & 400 & 15 \\
\hline
\end{tabular}

\begin{tabular}{|c|c|c|c|c|}
\hline $\begin{array}{l}\text { Casting } \\
\text { Simulations }\end{array}$ & $\begin{array}{c}\text { Actual Casting } \\
\text { of Parts }\end{array}$ & $\begin{array}{l}\text { Mechanical } \\
\text { Testing }\end{array}$ & $\begin{array}{c}\text { Finite Element Simulations and } \\
\text { Life Prediction }\end{array}$ & $\begin{array}{l}\text { Reliability } \\
\text { Assessment }\end{array}$ \\
\hline
\end{tabular}

Figure 2: Steps to develop a simulation-based methodology for evaluation of cast parts.

\subsection{Mould design optimization and casting of specimens}
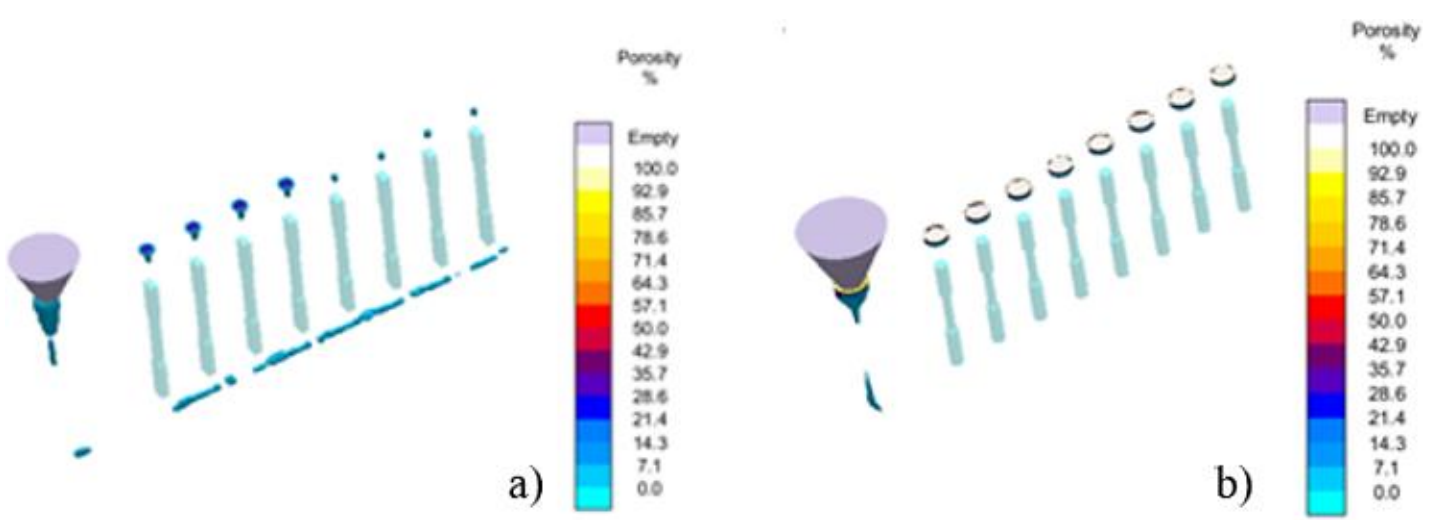

Figure 3: Simulation results (x-ray view) of porosity using optimized mould design for: a) tensile specimens and $b$ ) fatigue specimens.

It is conventional to draw standard specimens from already available cast plates, rods or even actual cast products to characterize them for mechanical properties and fatigue life. However, the work done here is more process oriented which brought about a need to consider these specimens as simple cast parts. Hence, moulds capable of producing number of specimens in a single casting run are designed, simulated, and further optimized using casting simulation software MAGMASoft. The details of mould design optimization as already presented in [12]. Fig. 3 shows the $\mathrm{x}$-ray view of simulation results of optimized mould designs for tensile and fatigue specimens indicating no porosity in both types of specimens. The optimized mould design is used to cast specimens at one of the local foundries. Post casting cleaning and finishing operations are done and the specimens are machined to final dimensions using ASTM E-8 standard for tensile testing and ASTM E-466 standard for fatigue testing.

\subsection{Tensile testing: experiments and simulations}

In total, five specimens are tested under tension where an excellent agreement is observed between the strength and ductility measurements of the sound (pore-free) and cast specimens [12]. Simulations of tensile testing are done in ABAQUS using elastic-plastic material model and porous metal plasticity model. Fig. 4 a compares the stress-strain curves for a sound 
specimen obtained through physical and simulated tensile testing. An excellent agreement between the experimental and simulated results suggests the appropriate modelling and selection of porous metal plasticity parameters [12]. The stress distribution within the specimen is shown in Fig. $4 \mathrm{~b}$ where the simulated and experimental fractures are also presented. With an excellent mapping of experimental and simulation findings in terms of elastic properties and fracture, it is plausible to use this model to predict the deterioration in mechanical properties (strength and ductility) and fracture behaviour when specimens are obtained with defects such as porosity.

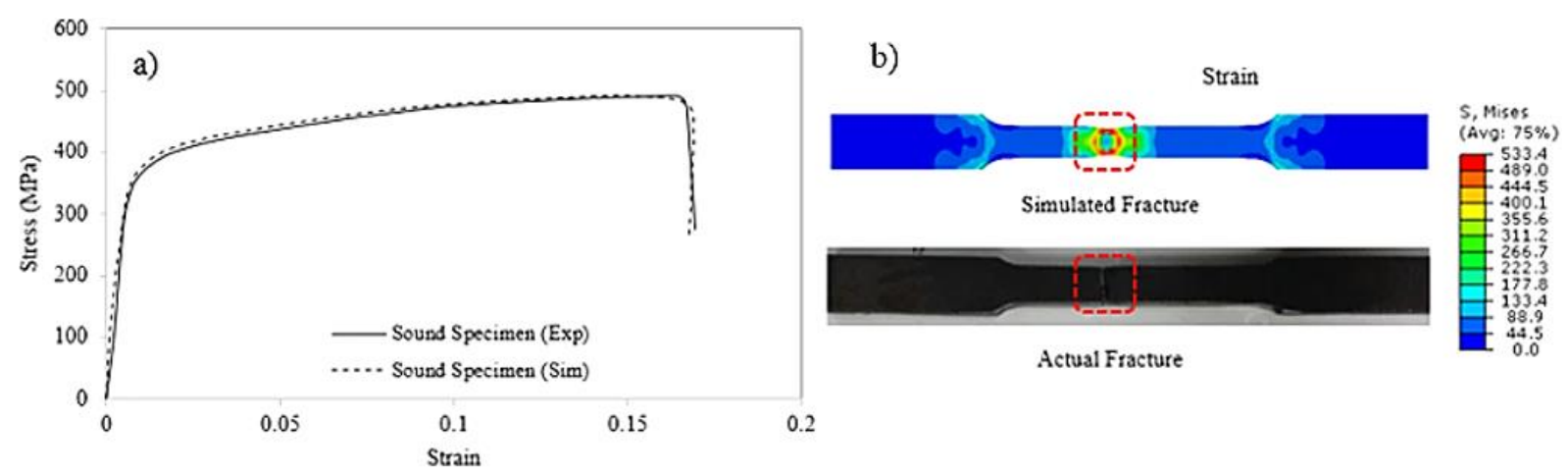

Figure 4: a) simulated and experimental stress-strain behaviour of sound specimen, b) simulated and actual fracture.

\subsection{Fatigue testing: experiments and simulations}

The cast specimens are also characterized for fatigue lives using load-controlled testing method. This method is preferred being simpler and faster as compared to strain-controlled fatigue testing. The loading conditions are set to be fully reversed which suggest $R=-1$ during testing. Even with the load-controlled mode, the testing of a specimen can take much longer if tested at a lower stress amplitude. Therefore, two different frequencies are used in testing i.e. $5 \mathrm{~Hz}$ and $10 \mathrm{~Hz}$ for higher and lower stress amplitudes respectively. All specimens are tested to fracture and the runout condition is set to $1 \times 10^{6}$ cycles in this study. In total seven specimens are tested under carefully selected stress amplitudes so that at least one specimen will experience the runout condition i.e. the infinite life. More details on fatigue testing can be found in previously published work [13].

Fatigue life of specimens are also predicted and compared with the experimental results. In doing so, a series of steps are followed. At first, the porosity results obtained in MAGMASoft simulations are translated to FEA mesh nodes where elastic properties are degraded as already described by Khan and Sheikh [12]. Next, elastic stress analysis is done for each specimen using the load conditions used in fatigue experiments. The stress field obtained as a result of this analysis is then imported to FE-safe (life prediction software) to perform a multi-axial strainlife analysis [13]. The software used Maximum Principal-Strain algorithm with Morrow mean stress correction [14] for life prediction. The measured and predicted fatigue lives are found to be an excellent agreement [13]. Despite such an agreement, incorporating micro-porosity in the analysis, which is bound to exist yet not predicted in casting simulations, can lead to further refinement of the results.

\subsection{Reliability assessment}

A conventional approach based on stress-strength interference theory is used to estimate specimens' reliability at predicted fatigue lives. Two scenarios are considered: (a) time independent load-induced stress, where no change in stress is considered over time, and (b) time dependent load-induced stress, which is more realistic as it considers the changes in stress 
over time [13]. For (a), the reliability is computed at four stress levels which are $90 \mathrm{MPa}$, $150 \mathrm{MPa}, 200 \mathrm{MPa}$, and $250 \mathrm{MPa}$. These values are selected based on the minimum and maximum load-induced stresses to be experienced by actual castings. Once again, FE-safe is used where variability in both the material fatigue strength and applied loading is considered while predicting the probability of failure for a specified life. For (b), which certainly provides more conservative reliability values, once again the stress-strength interference theory is applied, however, in this case the load-induced stress had to be modelled using Rayleigh distribution using analytical methods [15]. If the shape parameter $\beta$ in Weibull distribution becomes 2 , it represents the Rayleigh distribution which means that if $\beta$ for strength is twice the $\beta$ for strength i.e. $\beta_{S}=2 \beta_{\sigma}$, then the reliability analysis is done using Weibull distributed strength and Rayleigh distributed load-induced stress. The reliability function is given by:

$$
R=P(S>\sigma)=\frac{\theta_{S}}{\theta_{\sigma}} \sqrt{\pi} \cdot \exp \left(\frac{1}{4}\left(\frac{\theta_{S}}{\theta_{\sigma}}\right)^{2}\right) \cdot\left\{1-\phi\left[\frac{1}{\sqrt{2}} \cdot\left(\frac{\theta_{S}}{\theta_{\sigma}}\right)\right]\right\}
$$

The reliability can be estimated against the ratio of scale parameters i.e. $\frac{\theta_{S}}{\theta_{\sigma}}$ for the targeted lives. Here, the $\frac{\theta_{S}}{\theta_{\sigma}}$ ratio is approximated to be similar to that of the $\frac{S}{\sigma}$ ratios for the targeted lives.

Reliability results are then used to determine a safe load-induced stress for ductile iron [13]. Irrespective of the value of shape parameter ' $\beta$ ', more than $80 \%$ of the components perform well without failure at a stress level of $140 \mathrm{MPa}$ which is definitely a conservative estimate of safe loading. With higher values of $\beta$ such as 10 , it is evident that about $95 \%$ of the components can survive infinite life when loaded to $160 \mathrm{MPa}$. Therefore, $160 \mathrm{MPa}$ can be fairly considered as safe stress for infinite service life of ductile iron cast parts, one of which will be presented next in this paper. For time-dependent load-induced stress, it is observed that the design factor dictates the reliability. For a design, where strength ' $S$ ' is four times the stress ' $\sigma$ ', the components can expect to have $\sim 90 \%$ reliability which drops to $54.5 \%$ when $S=\sigma$.

The developed and experimentally validated simulation-based methodology explained from section 2.1 to section 2.4 is then applied to the selected cast valve body discussed above. The details of this implementation are explained in the forthcoming section.

\section{MOULD DESIGN OF VALVE BODY USING MAGMASOFT}

\subsection{Initial mould design}

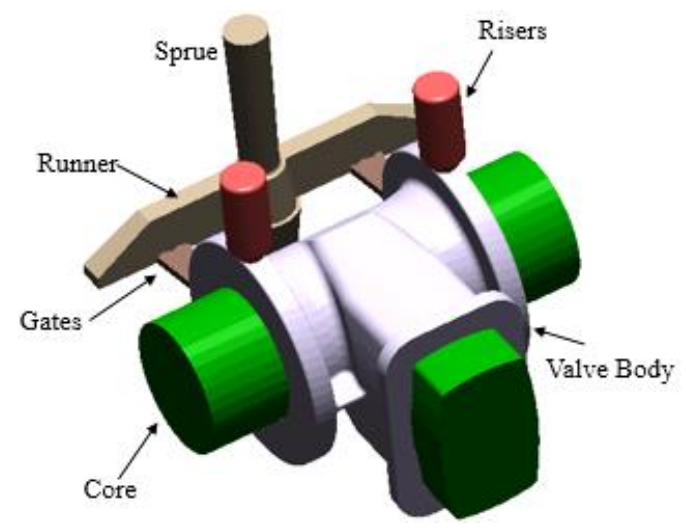

Figure 5: Initial casting layout for valve body.

The initial casting layout for valve body is prepared using standards, expertise of foundrymen and the mathematical formulations available in [16]. Due to geometry of the casting, two in-gates are used to supply the molten metal. Two-top risers are provided at those two ends of valve body which are connected to flanges during assembly. The initial casting 
layout for valve is shown in Fig. 5. The initial casting layout is simulated in MAGMASoft for filling and solidification behaviour and defects prediction. The casting layout is discretized into 2,927,232 elements using cubical mesh. Melt treatment is defined in the software in terms of inoculation method (Good), treatment yield (100\%) and graphite precipitation. The pouring time is set to be 17 seconds. The initial temperature of the melt and the mould are $1400^{\circ} \mathrm{C}$ and $40{ }^{\circ} \mathrm{C}$ respectively.
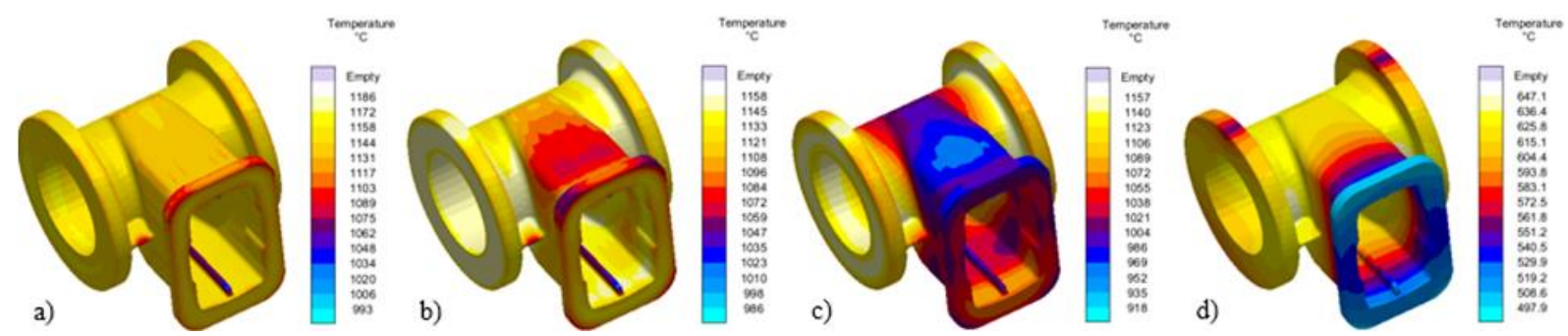

Figure 6: Temperature profile during solidification: a) $25 \%$, b) $50 \%$, c) $75 \%$, and d) $100 \%$.
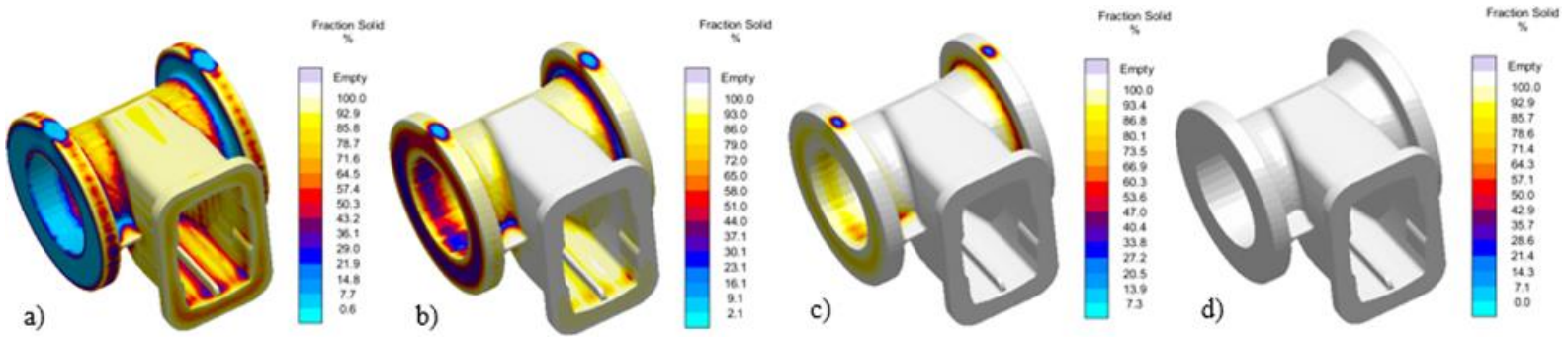

Figure 7: Solidification sequence: a) $25 \%$, b) $50 \%$, c) $75 \%$, and d) $100 \%$.

The results of casting simulations using initial mould design are presented in Figs. 6 to 9 . The temperature distribution in the valve at different stages of solidification is shown in Fig. 6. The temperature contour indicates the farthest point in casting with minimum temperature at $100 \%$ solidification which suggested the start of solidification from that point. This is also confirmed by percentage fraction solid results shown in Figs. 7 a to d. The residual stresses at ejection are $\sim 60 \mathrm{MPa}$ and the higher stresses are observed in thin sections of valve as shown in Fig. 8 a. Fig. 8 b shows the presence of hotspots within the valve body. These hotspots should be minimized to avoid shrinkage related defects. Simulated shrinkage porosities are presented in Fig. 9. Although, no surface porosity is observed in valve body, Fig. 9 indicates the regions with significant porosity which needs to be minimized to improve the overall quality of casting.
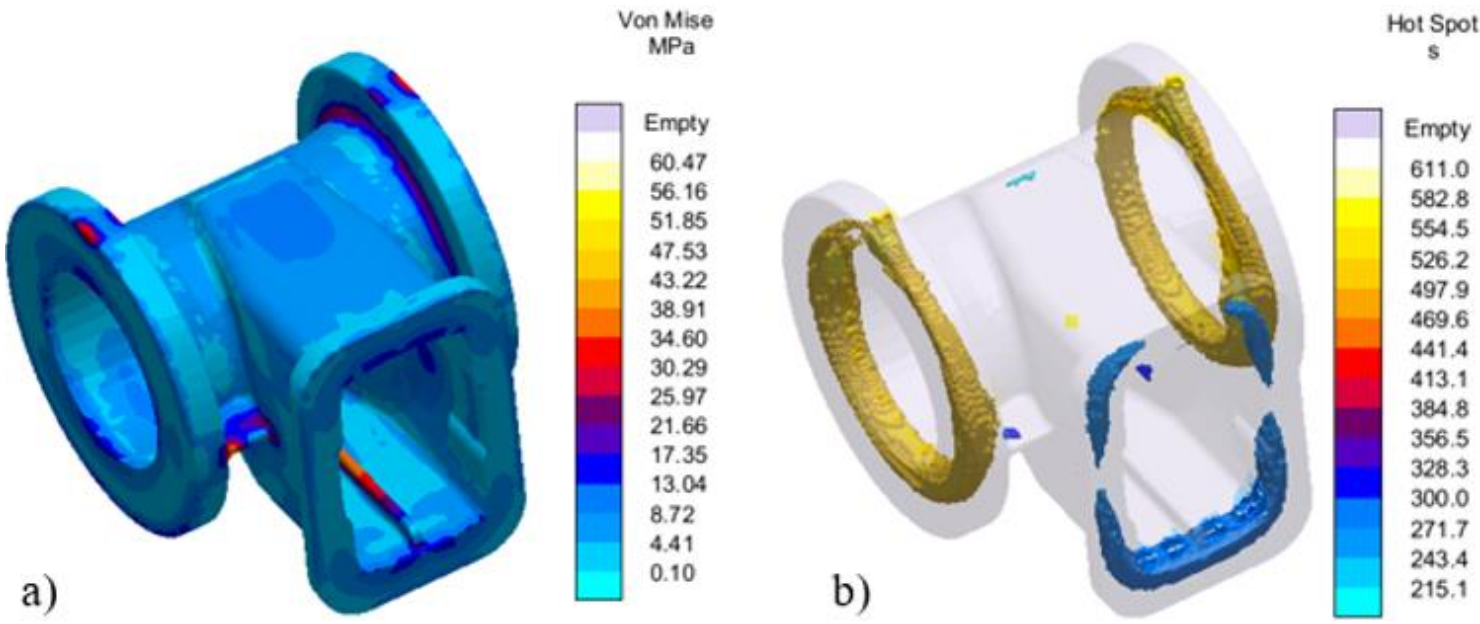

Figure 8: a) residual stress distribution, and b) hotspots in valve body using initial mould design. 


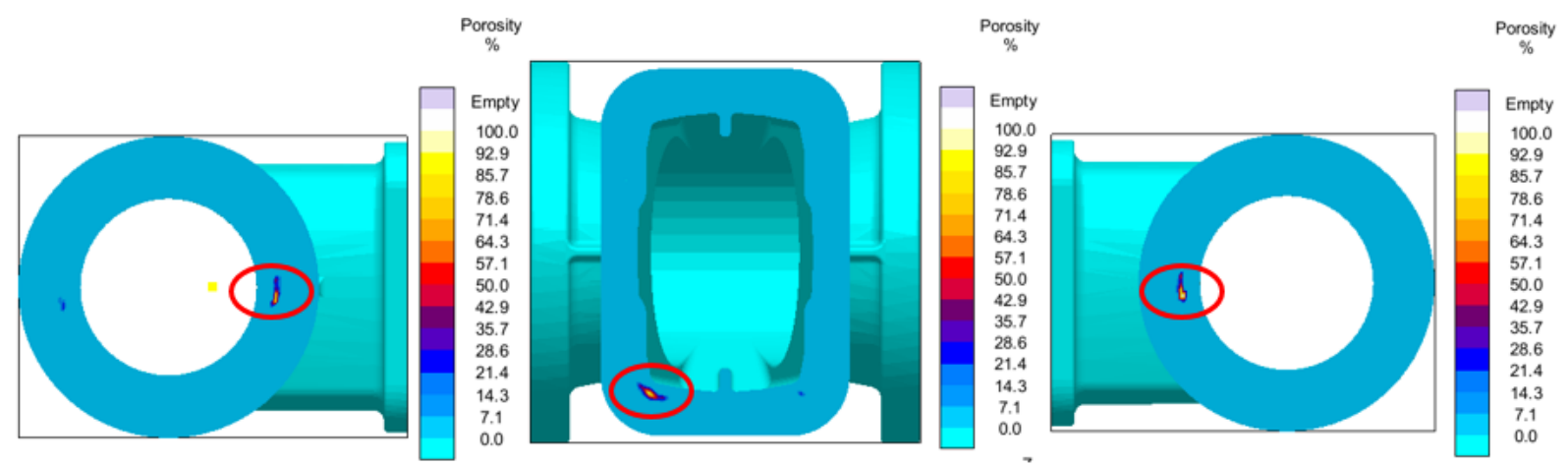

Figure 9: Porosity significant areas in valve body using initial mould design.

\subsection{Optimized mould design}

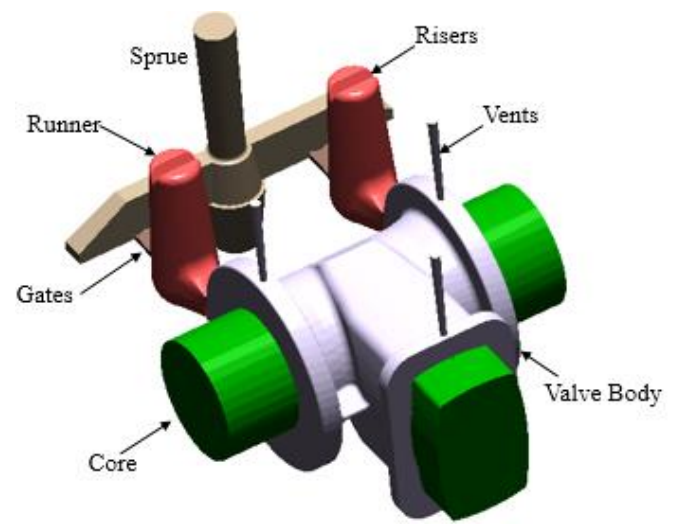

Figure 10: Modified casting layout for valve body.

Mould design optimization began with modifying the riser design. Top-risers are replaced by side risers as shown in Fig. 10. The casting is gated through the side riser for maximum efficiency. Moreover, the hemispherical bottom on the side riser prevent early freezing of the riser and casting junction [17]. In addition to this, vents are provided to permit the escape of entrapped gases within the cavity. The dimensions of the sprue and sprue well, runner and gates remained unchanged. The optimized casting layout is imported to MAGMASoft for simulation. A cubical mesh is used with 3,051,620 elements. The material properties, process parameters and pouring time remained unchanged. Once again, filling, solidification, and stress simulations are run to observe the filling and solidification sequence and to predict the defects such as hotspot and porosity.

The simulation results for optimized mould design are presented in Figs. 11 to 14. The temperature contours in Figs. 11 a to d depict the start of solidification from the farthest point from pouring i.e. the end of the valve where bonnet is attached. This is also confirmed through percentage fraction solid results as shown in Fig. 12.
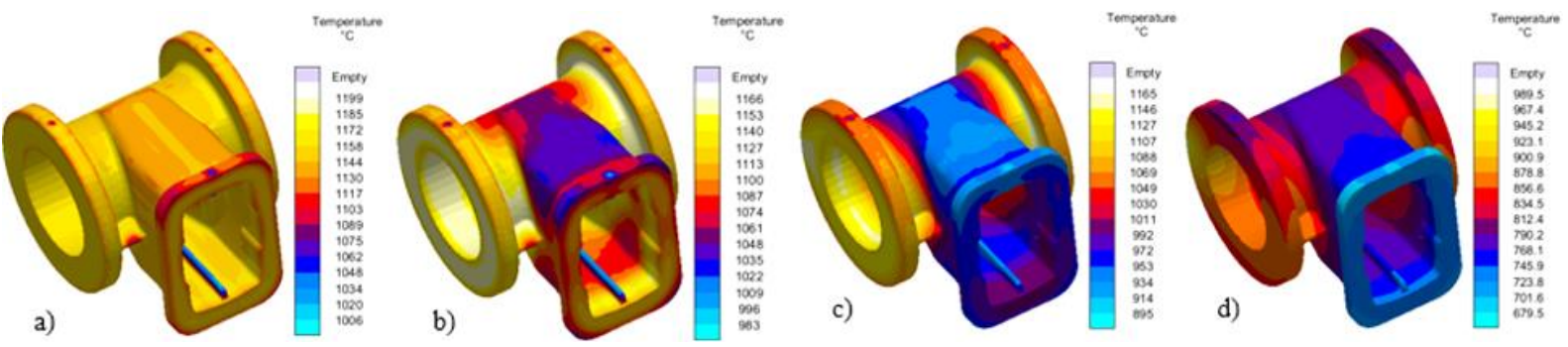

Figure 11: Temperature profile during solidification: a) $25 \%$, b) $50 \%$, c) $75 \%$, and d) $100 \%$. 


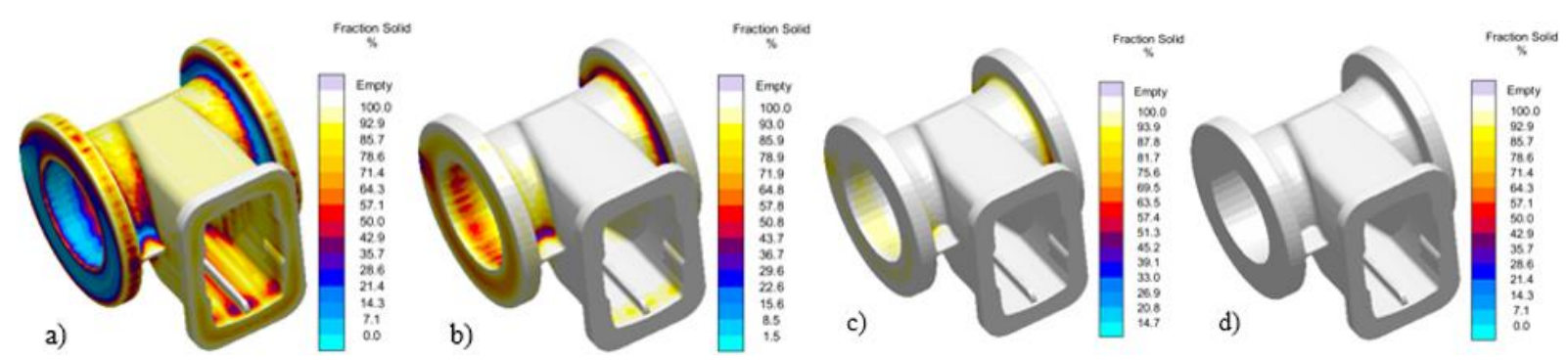

Figure 12: Solidification sequence: a) $25 \%$, b) $50 \%$, c) $75 \%$, and d) $100 \%$.
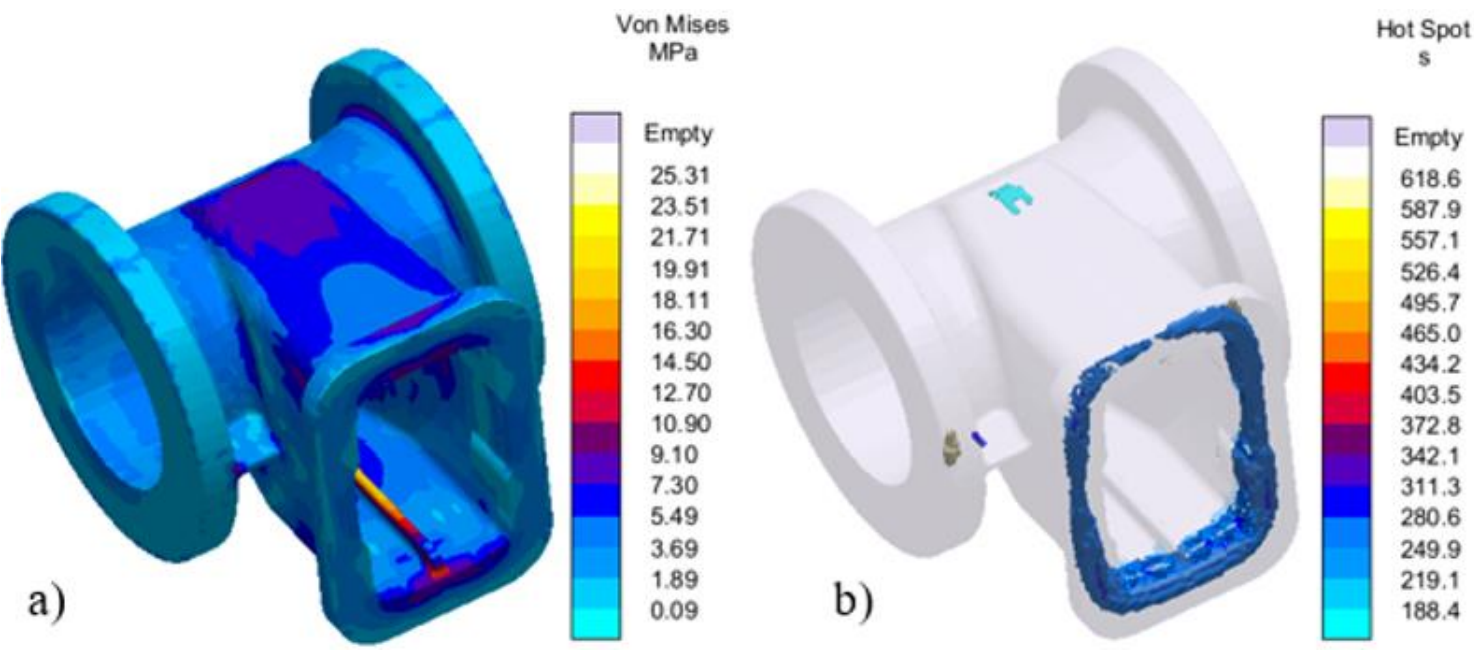

Figure 13: a) residual stress distribution, and b) hotspots in valve body using optimized mould design.

The residual stresses are significantly reduced from $\sim 60 \mathrm{MPa}$ to $\sim 25 \mathrm{MPa}$ with the optimized mould design as shown in Fig. 13 a, which suggests improved cooling and solidification. The hotspots are not completely eliminated as shown in Fig. 13 b, however, it is minimized when compared to the hotspot predicted in Fig. 8 b. Fig. 14 shows the areas of valve where the porosity was significant previously. It can be observed that the porosity is greatly reduced in all these areas. Although some porosity is observed in Fig. 14, however, the amount of porosity is fairly acceptable to consider this mould design for actual casting.

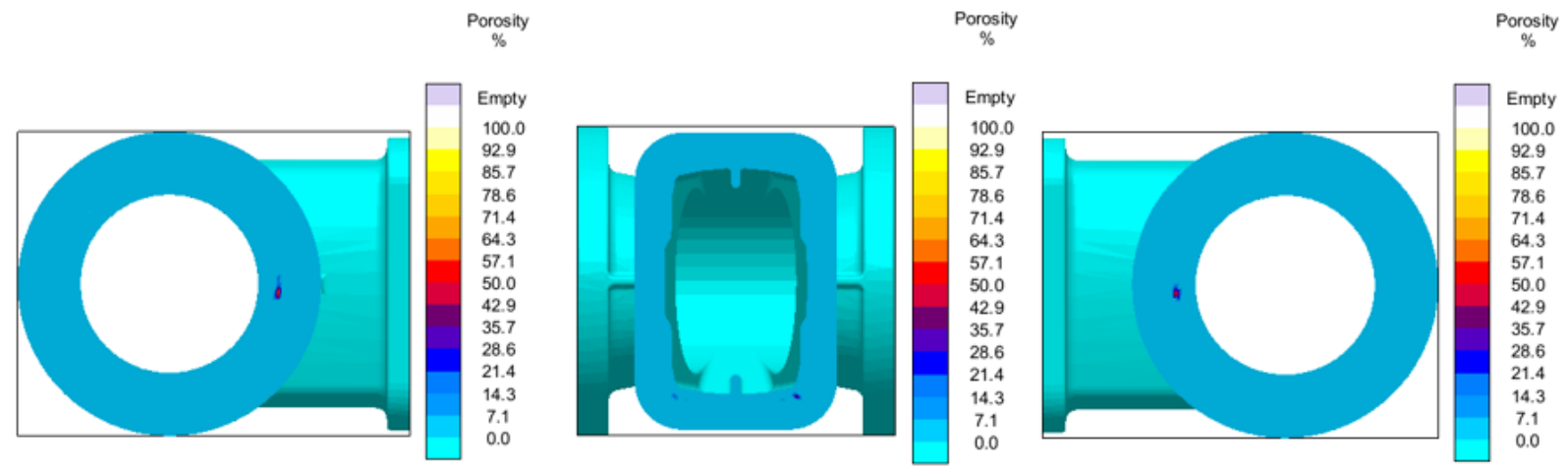

Figure 14: Porosity minimization in valve body using optimized mould design.

\section{FINITE ELEMENT SIMULATION AND FATIGUE LIFE PREDICTION OF VALVE BODY}

The finite element modelling of valve body is done using ABAQUS standard. The optimized mould design contains some porosity in the valve body which has to be included in FE analysis. The predicted porosity is incorporated to FE simulation using MAGMAlink. Valve geometry 
is imported to ABAQUS and discretized using a 10 node quadratic tetrahedron (C3D10) elements as shown in Fig. 15 a. The resulting mesh contained 101,451 elements and 162,056 nodes, when an $8 \mathrm{~mm}$ spacing is used. Experimenting with further mesh refinement shows no significant changes in the results. The mesh shown in Fig. 15 a is then imported to MAGMASoft using MAGMAlink and the predicted porosity is mapped to FEA nodes. The nodal porosity is then exported and integrated to ABAQUS simulations using the same procedure done for the specimens.
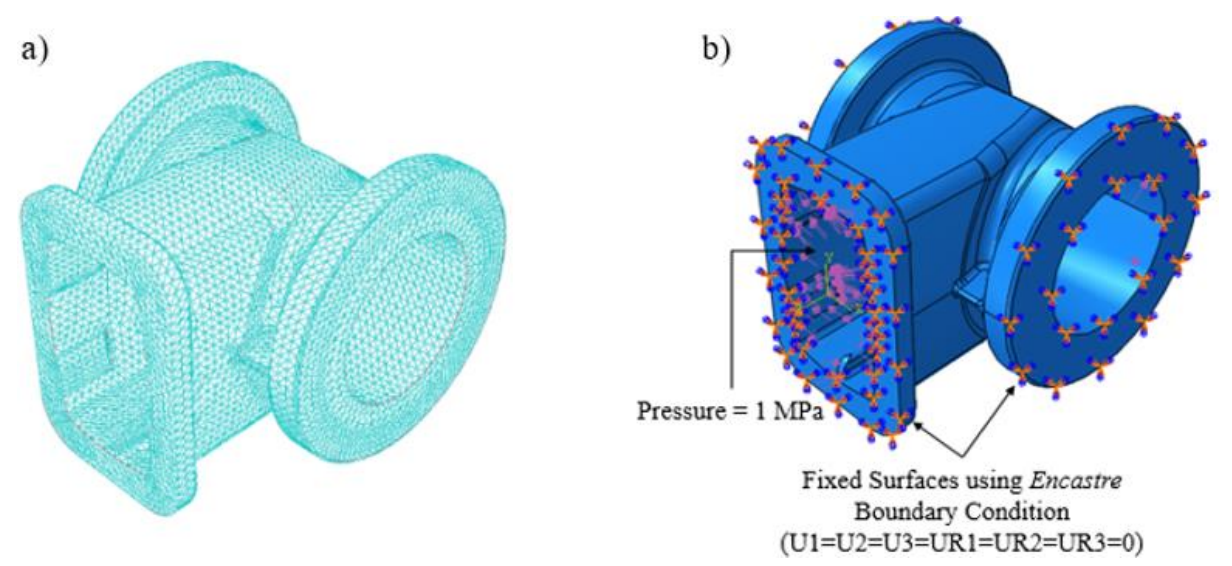

Figure 15: a) mesh for valve body in ABAQUS, and b) boundary conditions for FE simulation.

Next, the boundary conditions for FE simulations are carefully decided to replicate the actual conditions of valve body in service. The boundary conditions are set in consultation with MASABIK foundry based upon the information provided by the end-user. The pressure applied to the valve body in normal operating conditions is $1 \mathrm{MPa}$, however, it is communicated that it can sustain a maximum pressure of $2.5 \mathrm{MPa}$. The ends of the valve connected to flange and bonnet are fixed using encastre boundary conditions, whereas a pressure of $1 \mathrm{MPa}$ is applied to the internal surface of the valve body. Fig. $15 \mathrm{~b}$ shows the boundary conditions used in FE simulations.
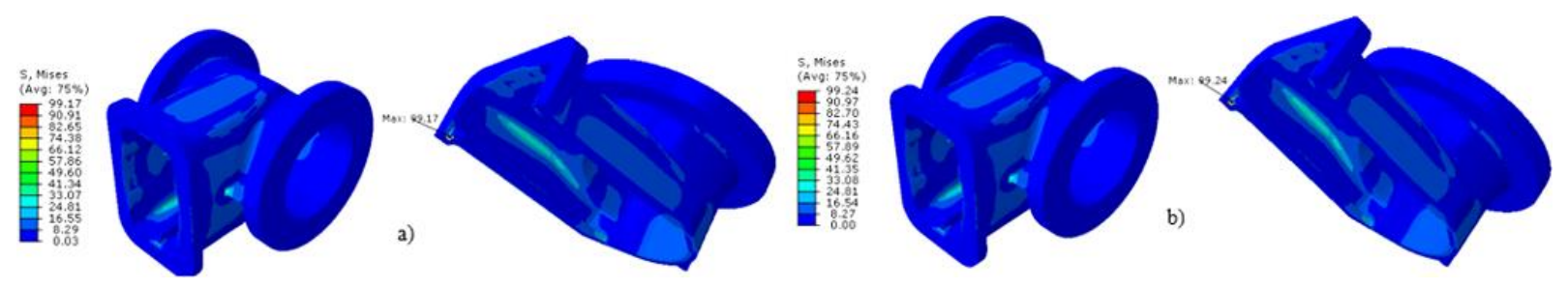

Figure 16: Von Mises stress results in valve body: a) without porosity, and b) with porosity.

The Von Mises stress results for the valve body with the above boundary conditions are presented in Fig. 16. Fig. 16 a shows the stress field without porosity i.e. Sound valve body. In this case, the maximum load induced-stress is found to be $299.17 \mathrm{MPa}$ which gives a safety factor of 2.8 for iron with a yield strength of $280 \mathrm{MPa}$. With porosity, the load-induced stress is not significantly change i.e. $\sim 99.24 \mathrm{MPa}$, thereby, resulting in same safety factor. The location of maximum Von Mises stress is also shown in Figs. 16 a and b. Using the factor of safety based on the fatigue endurance limit of $197 \mathrm{MPa}$, the factor of safety for the highest value of stress is $\sim 2$. Once again, these values of safety factors are deterministic and the probabilistic reliability computations will be presented.

The next step in the analysis is to predict the fatigue life with and without porosity. The porosity will be of concern if it lowers the fatigue life below $10^{6}$ cycles which is set as the runout condition in the present work. Fatigue life is predicted using FE-safe using the method discussed above in Section 2.3. The results of fatigue life prediction are presented in Fig. 17. 


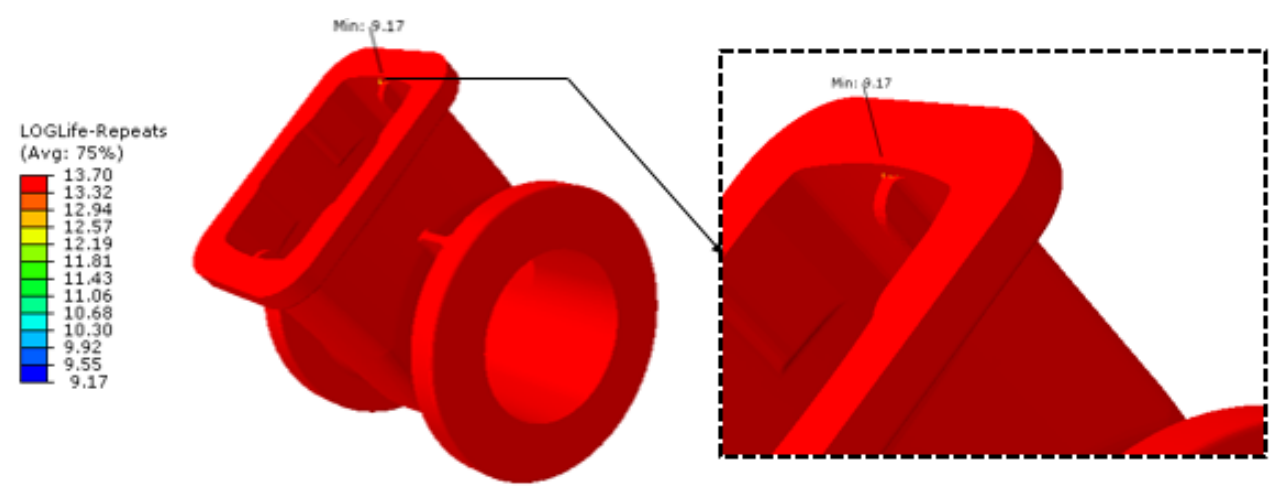

Figure 17: Fatigue life prediction of valve body using FE-safe.

The minimum fatigue life with and without porosity are found to be more than $10^{9}$ cycles which suggests the survival of the part in these predictions. It is observed that the small porosities predicted using optimized mould design did not affect the life of valve body. Hence, these results confirm the robustness of optimized mould design for casting valve body.

\section{RELIABILITY ASSESSMENT OF VALVE BODY}

In order to compute reliability of valve body, two load-induced stresses are used for calculations. The internal pressure applied to the valve under normal working conditions is $1 \mathrm{MPa}$, and maximum pressure that can be applied as provided by MASABIK foundry and enduser is $2.5 \mathrm{MPa}$. Therefore, the valve with porosity is simulated for stresses at these two loading conditions. The resulting stress fields are presented in Fig. 18. These stresses are then used in FE-safe for reliability computations. A $5 \%$ variability in load-induced stresses is considered and the material variability is represented by Weibull distribution with varying shape parameter $\beta$.
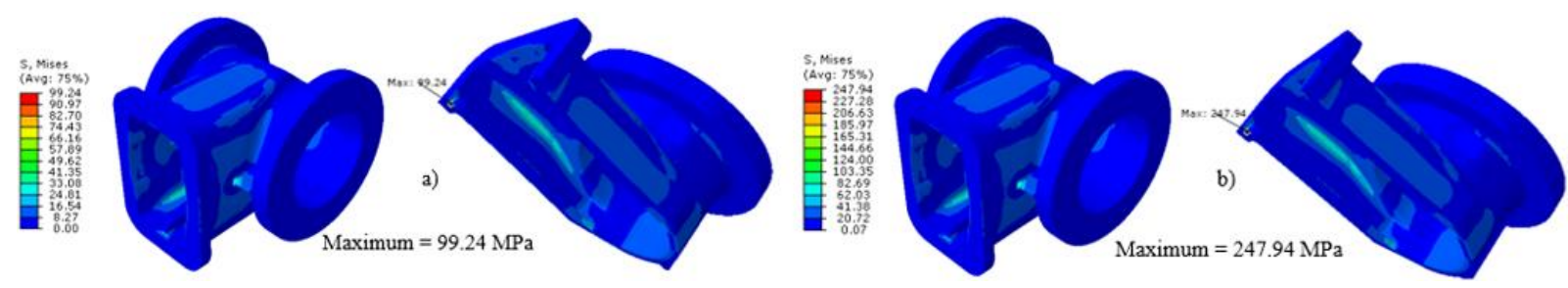

Figure 18: Von Mises stress in valve body with porosity at applied pressure: a) $1 \mathrm{MPa}$, and b) $2.5 \mathrm{MPa}$.
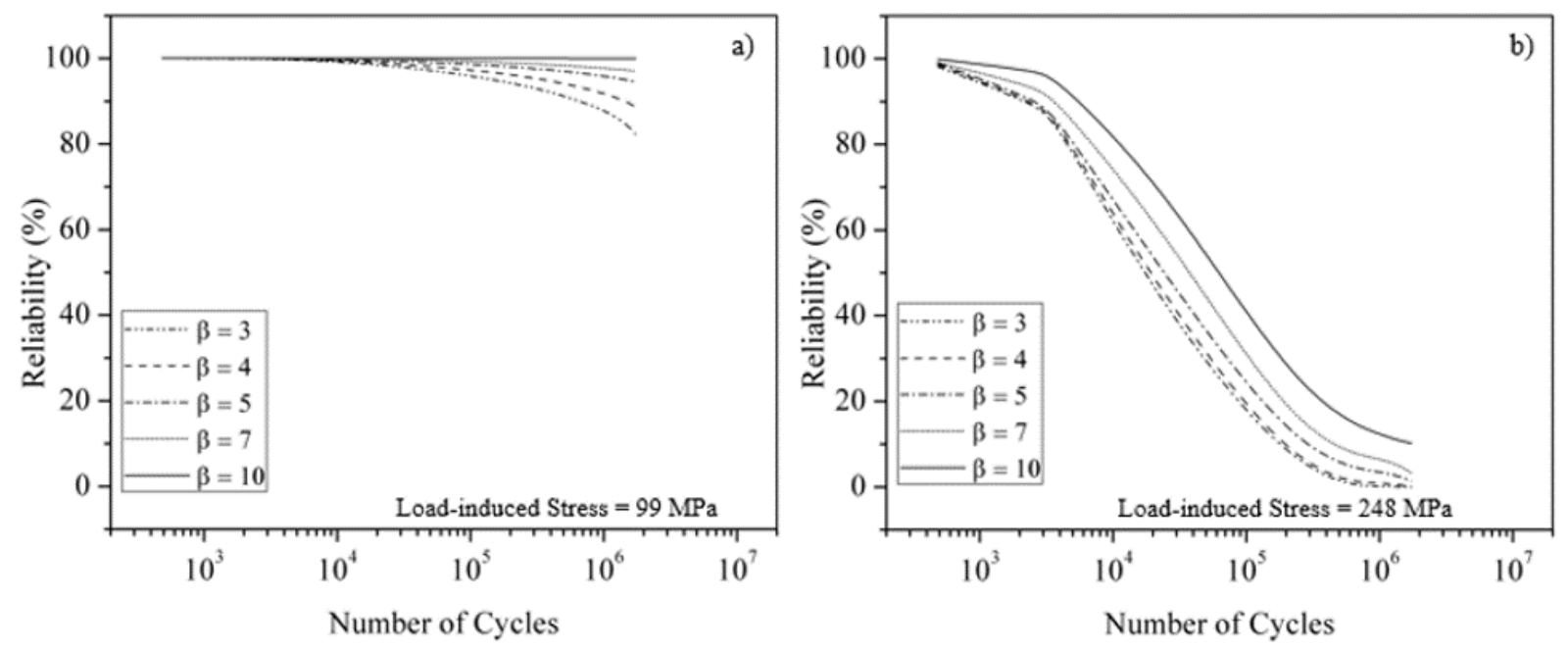

Figure 19: Reliability results with a load-induced stress of: a) $99 \mathrm{MPa}$, and b) $248 \mathrm{MPa}$ on valve body. 
The resulting reliability curves for both scenarios are presented in Fig. 19. Fig. 19 a shows the reliability results for an internal pressure of $1 \mathrm{MPa}$ on valve resulting in a load-induced stress of $99 \mathrm{MPa}$. The component shows nearly $100 \%$ reliability until the infinite life i.e. $10^{6}$ cycles when $\beta=10$. This higher $\beta$ represents the actual scenario where the parts are produced using optimized mould with minimized porosity and variability in the product. If the parts are not produced using optimized mould it would result in reliability estimates using a lower $\beta$ such as 3 or 4 . At lower $\beta$ values, the reliability dropped down to $\sim 80 \%$. With maximum pressure of $2.5 \mathrm{MPa}$ and the corresponding load-induced stress of $248 \mathrm{MPa}$, the reliability is significantly compromised. It can be observed in Fig. $19 \mathrm{~b}$ that reliability significantly dropped with increasing number of cycles. Even with a high value of $\beta=10$, only $11 \%$ components resulted in an infinite life. Moreover, at lower $\beta$ values, none of the component survives up to infinite life.

\section{CONCLUSION}

A simulation-based methodology for mould design, life prediction and reliability assessment is developed and experimentally validated for standard specimens. This methodology is then applied to a valve body. The optimized mould design for minimum porosities is obtained using MAGMASoft. Integration of predicted porosity to valve body is done using MAGMAlink. The stress fields with porosity are obtained using ABAQUS which are then used to predict life and estimate reliability. The results of fatigue lives prediction at normal and maximum load conditions are encouraging since the life in each case is predicted to be more than $10^{6}$ cycles (infinite life). The reliability results for valve under normal operating pressure i.e. $1 \mathrm{MPa}$ shows $\sim 100 \%$ reliability for infinite life, however, under the maximum loading conditions, the reliability is significantly compromised. Therefore, this valve body is suitable to be used under normal working conditions of up to $1 \mathrm{MPa}$ pressure, whereas the use of these cast valves at high pressures i.e. 2.5 $\mathrm{MPa}$ or more is not recommended. A safe load-induced stress on valve body must not exceed $160 \mathrm{MPa}$ based on the reliability results obtained in this study.

The present work can be extended further through autonomous optimization of mould design for more than one objectives such as porosity minimization, soundness, yield maximization, residual stress minimization etc. Also, a comprehensive tool can be developed by coupling casting simulations + mechanical performance simulation + reliability simulations. Although such integration is complex, it can greatly contribute to casting industry by reducing the product time, cost, and risks associated with performance during service life.

\section{ACKNOWLEDGEMENT}

This work is supported by The National Science, Technology and Innovation Plan (NSTIP), Saudi Arabia, under grant number 14-ADV890-04-R. The simulations presented in this study were done at Rapid Prototyping and Reverse Engineering Lab at King Fahd University of Petroleum and Minerals (KFUPM). Special thanks to MAGMA and KFUPM for their continuous support during this work. The authors would also like to acknowledge the supportive environment provided by Prince Mohammad Bin Fahd University to facilitate the preparation of manuscript and its publication.

\section{REFERENCES}

[1] Khan, M. A. A.; Sheikh, A. K. (2018). A comparative study of simulation software for modelling metal casting processes, International Journal of Simulation Modelling, Vol. 17, No. 2, 197-209, doi:10.2507/IJSIMM17(2)402

[2] Bhatt, H.; Barot, R.; Bhatt, K.; Beravala, H.; Shah, J. (2014). Design optimization of feeding system and solidification simulation for cast iron, Procedia Technology, Vol. 14, 357-364, doi:10.1016/j.protcy.2014.08.046 
[3] Sun, Y.; Luo, J.; Mi, G. F.; Lin, X. (2011). Numerical simulation and defect elimination in the casting of truck rear axle using a nodular cast iron, Materials \& Design, Vol. 32, No. 3, 1623-1629, doi:10.1016/j.matdes.2010.11.009

[4] Kovacic, M.; Brezocnik, M. (2018). Reduction of surface defects and optimization of continuous casting of 70MnVS4 steel, International Journal of Simulation Modelling, Vol. 17, No. 4, 667676, doi:10.2507/IJSIMM17(4)457

[5] Mourad, M. M.; El-Hadad, S.; Ibrahim, M. M.; Nofal, A. A. (2015). Effect of processing parameters on the mechanical properties of heavy section ductile iron, Journal of Metallurgy, Vol. 2015, Paper 931535, 11 pages, doi:10.1155/2015/931535

[6] Borsato, T.; Ferro, P.; Berto, F.; Carollo, C. (2017). Mechanical and fatigue properties of pearlitic ductile iron castings characterized by long solidification times, Engineering Failure Analysis, Vol. 79, 902-912, doi:10.1016/j.engfailanal.2017.06.007

[7] Foglio, E.; Gelfi, M.; Pola, A.; Goffelli, S.; Lusuardi, D. (2017). Fatigue characterization and optimization of the production process of heavy section ductile iron castings, International Journal of Metalcasting, Vol. 11, No. 1, 33-43, doi:10.1007/s40962-016-0112-9

[8] Labrecque, C.; Gagné, M.; Cabanne, P.; François, C.; Becret, C.; Hoffmann, F. (2008). Comparative study of fatigue endurance limit for 4 and $6 \mathrm{~mm}$ thin wall ductile iron castings, International Journal of Metalcasting, Vol. 2, No. 2, 7-17, doi:10.1007/BF03355424

[9] Hardin, R. A.; Beckermann, C. (2009). Prediction of the fatigue life of cast steel containing shrinkage porosity, Metallurgical and Materials Transactions A, Vol. 40, No. 3, 581-597, doi:10.1007/s11661-008-9755-3

[10] Hardin, R. A.; Beckermann, C. (2012). Integrated design of castings: effect of porosity on mechanical performance, IOP Conference Series: Materials Science and Engineering, Vol. 33, Paper 012069, 8 pages, doi:10.1088/1757-899X/33/1/012069

[11] Ferro, P.; Lazzarin, P.; Berto, F. (2012). Fatigue properties of ductile cast iron containing chunky graphite, Materials Science and Engineering: A, Vol. 554, 122-128, doi:10.1016/ j.msea.2012.06.024

[12] Khan, M. A. A.; Sheikh, A. K. (2018). Mechanical characterization and quality of iron castings using optimized mold design: simulations and experimental validation, The International Journal of Advanced Manufacturing Technology, Vol. 98, 799-809, No. 1-4, doi:10.1007/s00170-0182325-y

[13] Sheikh, A. K.; Khan, M. A. A. (2020). Fatigue life prediction and reliability assessment of ductile iron castings using optimized mold design, The International Journal of Advanced Manufacturing Technology, Vol. 106, No. 5-6, 1945-1966, doi:10.1007/s00170-019-04504-5

[14] Dassault Systemes UK Ltd. (2015). FE-safe User Manual, Dassault Systemes

[15] Samar Ali, S.; Kannan, S. (2011). A diagnostic approach to Weibull-Weibull stress-strength model and its generalization, International Journal of Quality \& Reliability Management, Vol. 28, No. 4, 451-463, doi:10.1108/02656711111121834

[16] Rio Tinto Iron \& Titanium Inc. (1987). Ductile Iron: The Essentials of Gating and Risering System Design, QIT-Fer et Titane Inc., Montreal

[17] Steel Founders' Society of America (2001). Feeding \& Risering Guidelines for Steel Castings, Steel Founders' Society of America, Crystal Lake 